Chen, W., \& Jia, J. (2016). Comparison of Online and Onsite Students' Learning Outcomes and Experiences in a Massively Open Online Course in China. Journal of Educational Technology Development and

\title{
Comparison of Online and Onsite Students' Learning Outcomes and Experiences in a Massively Open Online Course in China
}

\author{
Weichao Chen \\ University of Virginia \\ Jiyou Jia \\ Peking University
}

\begin{abstract}
This paper compares the achievements and learning experiences of onsite and online students participating in a Massively Open Online Course (MOOC) in China. Altogether 192 Chinese students learned face-to-face, and another 311 Chinese learners participated online. In regard to learning performance, onsite learners had a lower attrition rate than the online students. However, for learners who had completed all their learning assignments, no significant difference was detected between the onsite and online participants' average assignment scores, and they were equally likely to win two of the learning awards. As to their learning experiences, there was also no significant difference between the online and onsite students' ratings of technology quality and usability, instructional content, and the design of learning assessment. Students also reported the challenges that they had encountered and provided suggestions to improve their learning experiences. At the end of the paper, lessons learned from running the $M O O C$ are discussed. Findings from this first empirical study on a Chinese MOOC informs researchers and practitioners interested in introducing MOOCs to Chinese students.
\end{abstract}

Keywords: MOOCs, learning performance, learning experience, China, higher education, summer school

\section{Introduction}

MOOCs stands for Massive or Massively Open Online Courses. It has become the buzzword of higher education since 2012 (Daniel, 2012; Siemens, 2012). Despite the rapid explosion of MOOCs, most of the discussions on MOOCs mainly occurred in less academic settings such as through media reports and trade magazines, and only recently have studies exploring MOOC participant's learning experiences started to appear in peer-reviewed journals (Gasevic, Kovanovic, Joksimovic, \& Siemens, 2014; Liyanagunawardena, Adams, \&Williams, 2013; Siemens, Irvine, \& Code, 2013). 
Nevertheless, researchers have unanimously highlighted low completion rates as one of the major challenges of MOOCs, and more studies are still necessary to better understand students' learning experiences and to explore strategies that could contribute to their learning success (Gasevic et al., 2014; Jordan, 2014; Yang, Sinha, Adamson, \& Rose, 2013). The current project focused on the learning experiences and achievements of Chinese students enrolled in a Chinese MOOC. This first empirical study on a Chinese MOOC shed light on the experiences of Chinese students taking a MOOC. Furthermore, lesson learned from this study could inform practitioners working on introducing MOOCs to Chinese students and incorporating strategies that could support their successful completion.

This study was conducted within an annual summer school, "New Media and Learning," hosted by Peking University, one of the top universities in China. Since 2009, over 100 summer schools covering different subject areas have been offered for free by Peking university to graduate and undergraduate students all over the country. However, due to the limits of university's classroom capacity, in the past it was not possible to accept all the applicants. Therefore, in 2013, this summer school was organized as a MOOC to expand the enrollment, with both distance and faceto-face learners attending the same program together.

During implementation of this MOOC, there was a question that concerned not only the organizers, but also all the learners: were there any significant differences between the onsite and online students' learning outcomes and experiences? The organizers promised students that every effort would be made to ensure that both online and onsite participants would receive the same quality of education and be assessed in the same manner. Findings from this research could not only guide the organizers' future practices, but also inform other higher education institutions experimenting with MOOCs. Ensuring that distant learners taking a MOOC can achieve the same learning outcome as the on-campus students is of significance for certification. This summer school constituted a unique context to test the hypothesis.

Furthermore, as the first empirical study about a Chinese MOOC, findings from this project also guided both practitioners and researchers involved in the introduction of MOOCs to China. In their recent interviews (Gong, 2013a), the three most popular MOOC providers from the US, Coursera, Udacity, and edX, have unanimously expressed a strong desire to expand their reach to Chinese audience. Furthermore, observing the language barriers facing over half of their students who were from non-English speaking countries, Coursera launched a Global Translator Community (http://www.coursera. community/\#gtc) in 2014 and recruited volunteers to provide translated subtitles for their courses.

Language is just one of the issues facing Chinese students. A substantial amount of effort needs to be made to conduct trials and successfully introduce MOOCs and associated novel instructional practices to Chinese learners. Unfortunately, in their recent review of published literatures on MOOCs, Liyanagunawardena et al. (2013) noticed a significant lack of research addressing the learning experiences of students from Asia and called for more studies due to substantial differences between the Western and Eastern educational cultures and philosophies. This pioneering study reported the experiences of Chinese students taking a MOOC, discussed the challenges that they had faced, and also shared lessons learned from running the summer school. 


\section{Literature Review}

The term MOOCs was first proposed by Dave Cormier and Bryan Alexander in 2007 to depict an online course offered by George Siemens and Stephen Downes at the University of Manitoba in Canada (Daniel, 2012). Since then, other universities with elite higher educational institutions pioneering, started offering their courses online to hundreds or even more than ten thousand learners (Daniel, 2012; McAuley, Stewart, Siemens, \& Cormier, 2010).

Currently, practitioners and researchers of MOOCs are still exploring different modes of practices, and a consensus regarding the definition of MOOCs has yet been achieved (Daniel, 2012). However, there are several key features of a typical MOOC, which have been incorporated into the design of this summer school:

- Large numbers of geographically widely distributed learners are enrolled (Rodriguez, 2012).

- MOOCs represents a new stage of the open education movement (Liyanagunawardena et al., 2013) that advocates the sharing of free and open educational resources with other educators and students (Butcher, 2011). Learners are provided open access to instructional materials via web.

- Different from prior open educational resources, a MOOC features a structure. Course, or the "C" in "MOOC," means a pre-arranged sequence of learning experiences. In other words, a series of checkpoints and deliverables is integrated into the instructional design (Grimmelmann, 2013).

- Due to the structure of MOOCs, learners are encouraged to participate in discussions to support one another's learning when a course is "active" (Gillani \& Eynon, 2014).

- Facing the challenges of completing the assessment of a large number of students in a short amount of time, MOOC providers mainly adopt machine grading and peer assessment (Sandeen, 2013).

Although an increasing number of studies have been conducted to address MOOCs' educational implications (Liyanagunawardena et al., 2013), there still exists a significant lack of research investigating MOOC participants' learning performance and experiences. Consequently, relevant studies of traditional online education are also included in the following literature review.

In terms of learning performance, prior studies reported that online students had dropout rates ranging from $10 \%$ to over $50 \%$ or even $80 \%$ (Bonk \& Khoo, 2014; Jaggars \& Xu,2010; Simpson, 2013). In China, traditional universities have started delivering distance education programs via Internet since 1998, and Chinese scholars have reported dropout rates between $10 \%$ and $15 \%$, lower than the rates from Western institutes $(\mathrm{Li}$, Zhou, \& Fan, 2014; Zhu, Bi, Qi, Li, Chen, \& Song, 2011).

The completion rates of MOOCs seemed to be much lower than those of regular online education programs. An initial report by Katy Jordan (2014) revealed that only a small portion of the learners enrolled in a MOOC had completed the course. Their completion rates ranged from $0.9 \%$ to $36.1 \%$, and the median value was as low as $6.5 \%$.According to the more recent data published by Jordan on June 12th 2015, the average dropout rate of over $200 \mathrm{MOOCs}$, the majority of which offered by Western institutes, was 
approximately $85 \%$. Analysis of Chinese learners' dropout rates can enrich the current exploration regarding MOOC participants' learning performance and also constitutes the first step to explore useful strategies supportive of student success.

Furthermore, studies abound that compare students' achievement in distance and traditional education programs. In a metareview of 232 studies conducted between 1985 and 2002(Bernard et al, 2004), the average effect size representing the difference in student achievement between distance and traditional programs was close to zero, slightly favoring distance education, while a huge variability around the mean was detected. Moreover, despite objections from prestigious researchers including Clark (1994), the number of studies comparing learners' performance in distance and traditional programs did not decrease with time. Bernard et al (2004) further discussed the meaningfulness of findings from sucha comparison within the context of global expansion of online education. Accounts of the rich contextual factors contributing to the success and failure of a distance education program inform decision makers regarding how to allocate their efforts between developing new distance education programs and enhancing traditional ones. Similarly, findings from this study that compare onsite and online students' performances in MOOCs are helpful for practitioners who are considering expanding the enrollment of their traditional programs in the form of MOOCs.

In regard to students' learning experiences, Bonk and Khoo (2014) recently surveyed existing literature and summarized factors that affected the success of online learners, including learners' lack of skills and other personal challenges, factors related to course design and instructional interaction, and issues due to technology access and usability. Studies of MOOC participants' experiences have highlighted issues related to social interactions, self-regulation of learning, motivation, difficulty with understanding instructional content, and access to learner support (Gasevicet al., 2014; Hew\& Cheung, 2014; Yang et al., 2013). Similarly, Chinese researchers voiced concerns over Chinese students' language difficulties and also their lack of self-directed learning skills and sustained motivations, which might influence their successful completion of MOOCs (Liu, 2013a, 2013b, 2013c). However, systematic research has not yet been conducted to investigate Chinese students' learning experiences in MOOCs, which is addressed in this study.

\section{Design of the summer school}

\subsection{Invitation of participants from all over the China}

The current two-week summer school, being offered for the fifth time, focused on the usage of new media in learning and teaching. Because this was the first time this summer school was provided online, a medium-size MOOC was experimented.

The summer school was advertised through the institute's Website and mailing list, the popular Chinese microblogging service of "Sina Weibo" (http://weibo.com/ gsesummer2013), and the widely adopted Chinese instant messaging service of "QQ." Paper posters were also mailed to 60 Chinese universities offering an educational technology degree. Applicants were asked to submit their resumes and recommendation letters. The summer school had drawn widespread attention, and 503 applications were received within less than four weeks. They were from 21 provinces, four autonomous regions, and four municipalities of China. All of these 503 
applicants were accepted. This number was 2.5 times of the number that had been enrolled in the previous year. Eventually 192 students were enrolled as onsite attendees, who came to Peking University's campus and learned face-to-face; another 311 students participated online. This grouping was randomly determined, taking into consideration students' preference while ensuring that each university had at least one student enrolled as an onsite member.

\subsection{Design of instructional and assessment activities}

Intensive learning experience was arranged for students during this summer school, including sixteen instructional sessions led by different experts and other instructional events listed in Figure 1. As summarized below, instructional design of the summer school focused on the three categories of instructional activities identified by Moore (1989).

Learners' interactions with the content: Moodle, an open source Course Management System (CMS), was localized and adopted. For each instructional session, presentation files and reading materials prepared by the instructor were uploaded beforehand to the CMS

After each instructional session, all the students were required to complete one to three online quizzes before the next day. Most of the quizzes were composed of multiplechoice questions only. Students' responses were automatically scored by the CMS. A few instructors designed essay questions and asked their graduate assistants to help with grading. Additionally, all the students were asked to submit a final paper focusing on any topic addressed during this summer school.

\section{Learners' interactions with the}

instructors: During the summer school, 15 educational technology experts were invited to present on various topics, including eight professors from different Chinese universities and seven overseas experts.

Each instructional session lasted for three hours. Experts designed the sessions on their own, and their teaching styles varied dramatically. Some of them incorporated a variety of active learning activities, while others mainly lectured and invited learners to respond to their questions and to raise questions during the presentation.

All the onsite learners attended the instructional sessions in the classroom, while the online students watched the live broadcasts. Students were required to sign in online within 30 minutes at the beginning of each session and sign out within 30 minutes at the end of the session. Their attendance rates were recorded by the CMS.

Learners' interactions with their peers: In order to encourage collaborative learning, students were assigned into 50 groups of 10 to 11 students. Efforts were made to ensure that each group consisted of members from different universities and regions of the country, learners with different genders and educational levels, and both onsite and online participants.

Some of the instructors designed group activities for the students to work together, and some posted questions to the online forums inviting learners to share their ideas. The learners, however, initiated most of the online discussions. They used the forums to hold discussions related to the presentation content and raise questions to seek support.

Additionally, students conducted peer assessment of their group members' final reports and submitted their results online. 
On the last day, a group presentation session was arranged. Students whose final paper scores were highest among their members represented their group and made a 5-minute presentation to introduce their team members and the group's best paper. All team members contributed to the preparation of their group presentation.

Certification and learning awards. A certificate of completion and three credits from Peking University were granted to the participants who fulfilled these three requirements: their average attendance rate was greater than $80 \%$, a final paper was completed, and their average assignment score was greater than 80 (out of 100). Learning awards were also granted to further motivate students' learning:

- Excellent Paper Award: The CMS automatically calculated an average final paper score for each student based on the peer assessment results. Altogether 51 students who had earned the highest grade among their group members were awarded.

- Excellent Participation Award: Sixty- five learners whose average attendance rate and average assignment score were both among the top $10 \%$ of the entire class received this award.

- Excellent Group Member Award: During their group presentations, students rated other teams' presentation and submitted their ratings online. Based on a ranking of all the groups' average ratings, thirty-nine students from the top five teams were awarded.

Both certificates and awards were presented to the students who attended the closing ceremony. Those who were not able to come received theirs via postal mail.

\section{Method}

In this study, online and onsite students' learning achievements were compared. Their completion rates, assignment scores, and performance in obtaining learning awards were analyzed. Furthermore, an online survey was designed in order to collect feedback from the learners and to compare onsite and online students' learning experience.
Week 1 Day 1

\section{Week 1 Day 2}

9:00am-12:00pm: Expert-led instructional session

2-5pm Expert-led instructional session

\section{Week 2 Day 1}

Week 2 Day 2

9:00am-12:00pm: Expert-led instructional session

2-5pm Expert-led instructional session 2-5pm Group visit to a digital publishing company 2pm: Final paper due
Week 2 Day 5

$8 \mathrm{am}-12 \mathrm{pm}$ and 1 2pm: Group presentations 4-5pm Closing ceremony

Figure 1. Overview of summer school schedule. 
The development of this survey instrument was guided by previous studies that analyzed students' experiences with blended or online learning (Akkoyunlu \& Yilmaz-Soylu, 2008; López-Pérez, Pérez-López, \& RodríguezAriza, 2011; Paechter, Maier, \& Macher, 2010; Shee, \& Wang, 2008; Sun, Tsai, Finger, Chen, \& Yeh, 2008). Researchers surveyed learners' overall perspective about the learning mode and process, and they asked students for feedback about the specific aspects of their learning experiences:

- Technology quality and user-friendliness of the Web environment

- Quality of instructional interaction

- Quality of instructional content

- Design of learning assessment

In the survey, students were asked to rate their satisfaction with these aspects of learning experiences in addition to providing an overall rating of satisfaction. The survey also asked for their prior experiences with online learning and MOOCs. At the end of the summer school, this survey was distributed. All the students were invited to respond to the survey on a voluntary basis. Altogether 163 onsite and 136 online students completed the survey.
Their self-reported learning experiences were compared. Additionally, learners were asked to provide qualitative feedback about their learning experiences. Students' comments were analyzed by two researchers, and the grounded theory approach was adopted (Strauss \& Corbin, 1990). A coding scheme was proposed based on reviewing students' feedback followed by discussion between the coders. This coding scheme was then adopted to categorize learners' comments.

Table 1 lists students' self-reported demographic information. The average ages of onsite and online students were both in the mid-20s, and there were more female than male students in both groups. Figures 2 and 3 demonstrate the wide distribution of the students according to province-level divisions of China.

According to Figures 4 and 5,67\% of onsite and $81 \%$ of online participants were master degree students. The rest were undergraduates, doctoral degree students, and non-students, including instructors in high school or universities or other practitioners in the field of educational technology. Additionally, over $80 \%$ of both onsite and online learners majored in educational technology (see Figures 6 and 7).

Table 1. Demographic Information of Survey Participants.

\begin{tabular}{lccccccccc}
\hline & \multicolumn{3}{c}{ Male } & \multicolumn{3}{c}{ Female } & \multicolumn{3}{c}{ Age } \\
\cline { 2 - 8 } & & $\mathrm{N}$ & $\%$ & $\mathrm{~N}$ & $\%$ & Mean & Median & Min & Max \\
\hline Onsite & 39 & 24 & 124 & 76 & 26.15 & 24 & 20 & 50 \\
Online & 18 & 13 & 118 & 87 & 25.41 & 24 & 19 & 42 \\
\hline
\end{tabular}




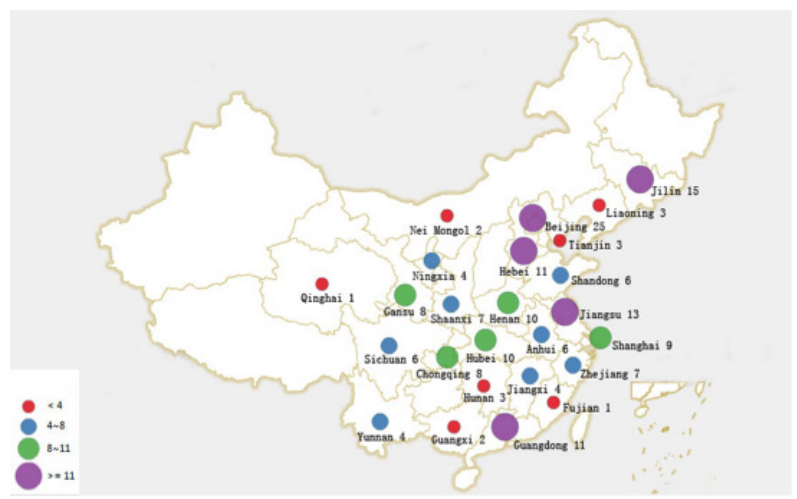

Figure 2. Onsite students' geographical distribution.

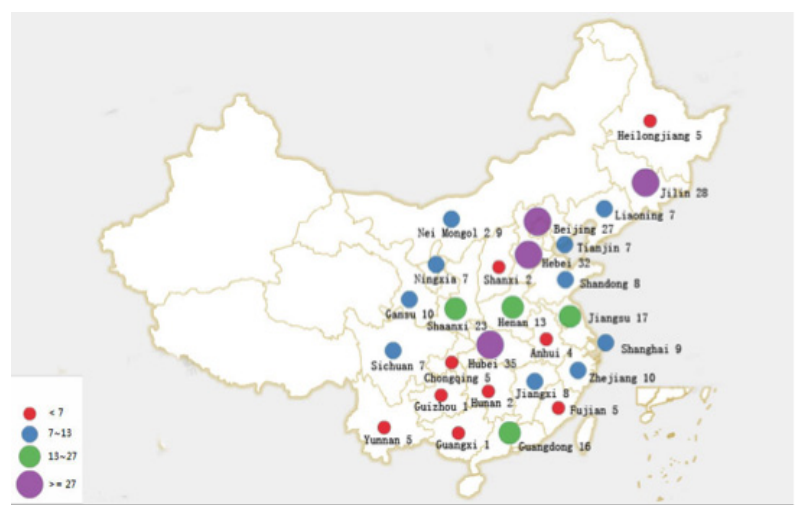

Figure 3. Online students' geographical distribution.

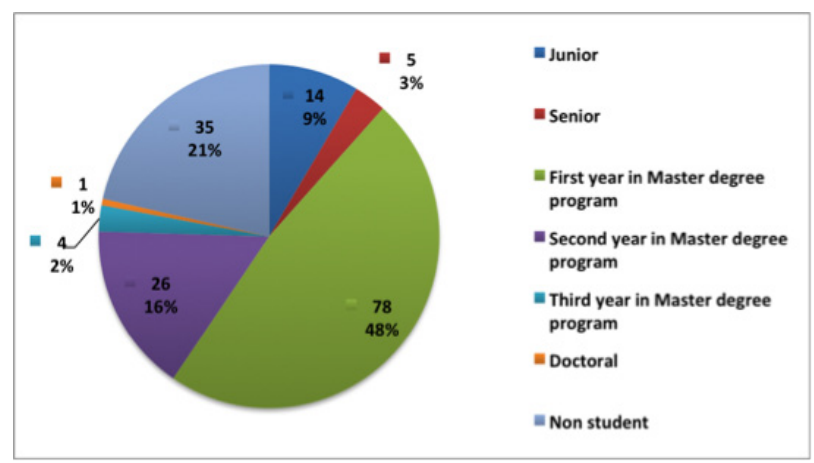

Figure 4. Onsite students' degree distribution. 


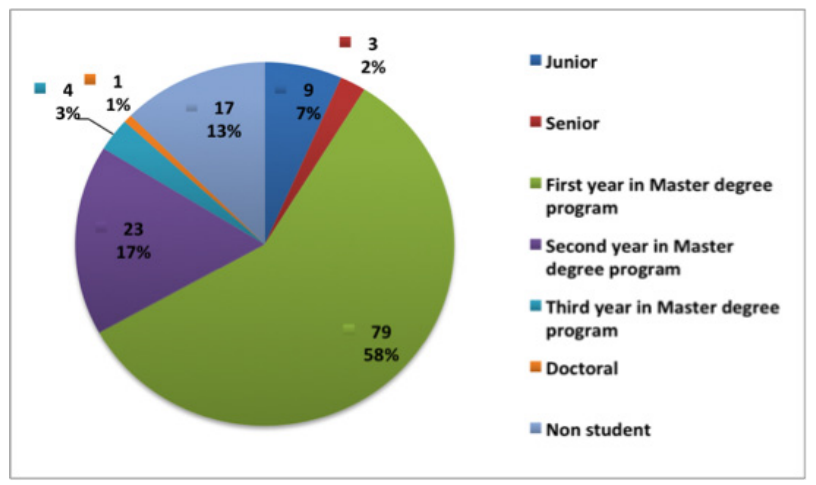

Figure 5. Online students' degree distribution.

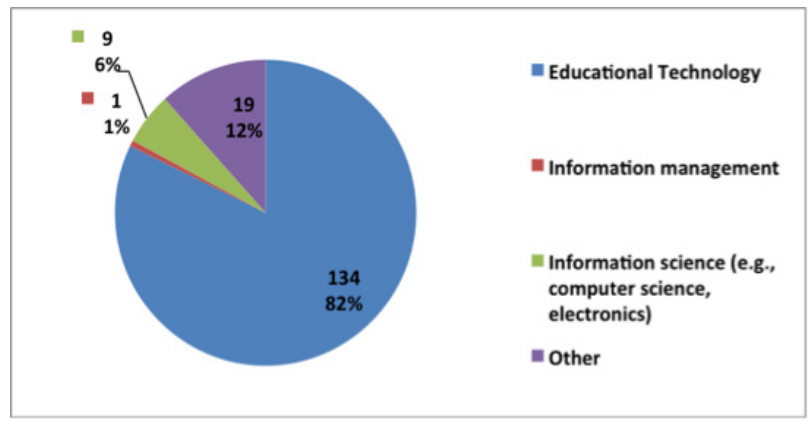

Figure 6. Onsite students' major distribution

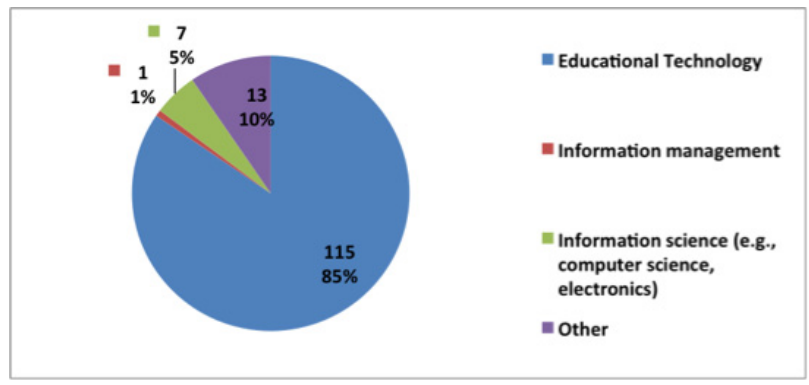

Figure 7. Online students' major distribution 


\section{Results}

\subsection{Learning performances}

\subsubsection{Attrition and Completion rates}

Altogether $88 \%(169 / 192)$ of onsite and $41 \%$ (128/311) of online students received the final certificate, totaling 297 learners. Table 2 lists the number of assignments completed by each group (out of the total 17 assignments). Only $8 \%$ of onsite learners did not complete any assignments, while this percentage for online students was $36 \%$. In contrast, only $30 \%$ of online students finished all of the assignments, while $77 \%$ of onsite learners were able to do so.

\subsubsection{Assignment Scores and Learning Awards}

In Table 3, the researchers compared the onsite and online learners' average assignment scores. The full score for each assignment was 100. For learners who had completed all 17 assignments, the average scores (89.99 vs. 90.13 ) and the percentages of students whose average score was above 85 (95\% vs. 96\%) were almost equivalent between onsite and online groups. A two-independent sample t-test was administered to compare the average scores of the onsite and online learners who had completed all the assignments, and no significant difference between their learning performance was detected, $\mathrm{t}(238)=-0.40, \rho=$ .689 .

A two-independent sample t-test was also conducted to compare the final essay scores between online and onsite learners who had completed all the assignments, and onsite students' average final paper score (Mean=92.39) was statistically significantly higher than that of online learners $($ Mean $=90.89), \mathrm{t}(238)=2.79, \rho=.006$.

Next, Pearson's chi-square tests were conducted to compare the performances of

Table 2. Number of assignments completed by the students.

\begin{tabular}{lcccccccc}
\hline & \multicolumn{3}{c}{ No. of assignment(s) completed } & \multicolumn{3}{c}{ Total } \\
\cline { 2 - 8 } & 17 & $16-11$ & $6-10$ & $1-5$ & 0 & $11-17$ & $1-17$ & $0-17$ \\
\hline Onsite & & & & & & & & \\
$\mathrm{N}$ & 147 & 23 & 2 & 4 & 16 & 170 & 176 & 192 \\
$\%$ (in 1-17) & 84 & 13 & 1 & 2 & & 97 & 100 & \\
$\%$ (in 0-17) & 77 & 12 & 1 & 2 & 8 & 89 & 92 & 100 \\
Online & & & & & & & & \\
N & 93 & 47 & 22 & 36 & 113 & 140 & 198 & 311 \\
$\%$ (in 1-17) & 47 & 24 & 11 & 18 & & 71 & 100 & \\
$\%$ (in 0-17) & 30 & 15 & 7 & 12 & 36 & 45 & 64 & 100 \\
\hline
\end{tabular}


onsite and online students in receiving each learning award, focusing on the students who had completed all the assignments.

- The percentage of students on campus who had earned Excellent Paper Awards $(26 \%)$ was significantly higher than that of distant learners $(12 \%), \chi^{2}(1, \mathrm{~N}=240)$ $=6.89, \rho=.009$.

- Although the percentage of online learners (29\%) who had won Excellent Participation Awards was higher than the percentage of onsite learners $(24 \%)$, the difference was not statistically significant, $\chi 2(1, \mathrm{~N}=240)=.81, \rho=.368$.

- With regard to receiving Excellent Group Member Awards, no statistically significant difference was detected between the performances of onsite (12\%) and online $(13 \%)$ groups, $\chi 2(1, \mathrm{~N}=240)$ $=.02, \rho=.881$.

\subsection{Survey findings}

\subsubsection{Previous experiences}

Pearson's chi-square tests were conducted to compare online and onsite students' self-reported learning experiences prior to attending this summer school, and no statistically significant difference was detected (see Table 4):

- experiences with blended-learning, $\chi^{2}$ (1, $\mathrm{N}=299)=0.24, \rho=.628$;

- $\quad$ open educational resources usage, $\chi^{2}$ (1, $\mathrm{N}=299)=0.20, \rho=.659$; and

- $\quad$ experiences with MOOCs, $\chi^{2}(1, \mathrm{~N}=299)$ $=1.49, \rho=.223$.

Table 3. Average assignment scores.

\begin{tabular}{cccccc}
\hline & Total & Average & S.D. & N & $\%$ \\
\cline { 5 - 5 } Onsite & & & & & \\
17 & 147 & 89.99 & 2.79 & 140 & 95 \\
$17-11$ & 170 & 89.64 & 3.51 & 159 & 94 \\
$17-6$ & 172 & 89.45 & 4.09 & 160 & 93 \\
$17-1$ & 176 & 88.57 & 8.46 & 160 & 91 \\
Online & & & & & 96 \\
17 & 93 & 90.13 & 2.12 & 89 & 89 \\
$17-11$ & 140 & 89.09 & 4.25 & 124 & 73 \\
$17-6$ & 162 & 87.37 & 7.22 & 129 & 144 \\
$17-1$ & 198 & 84.27 & 14.09 & 149 & \\
\hline
\end{tabular}


Table 4. Prior learning experiences.

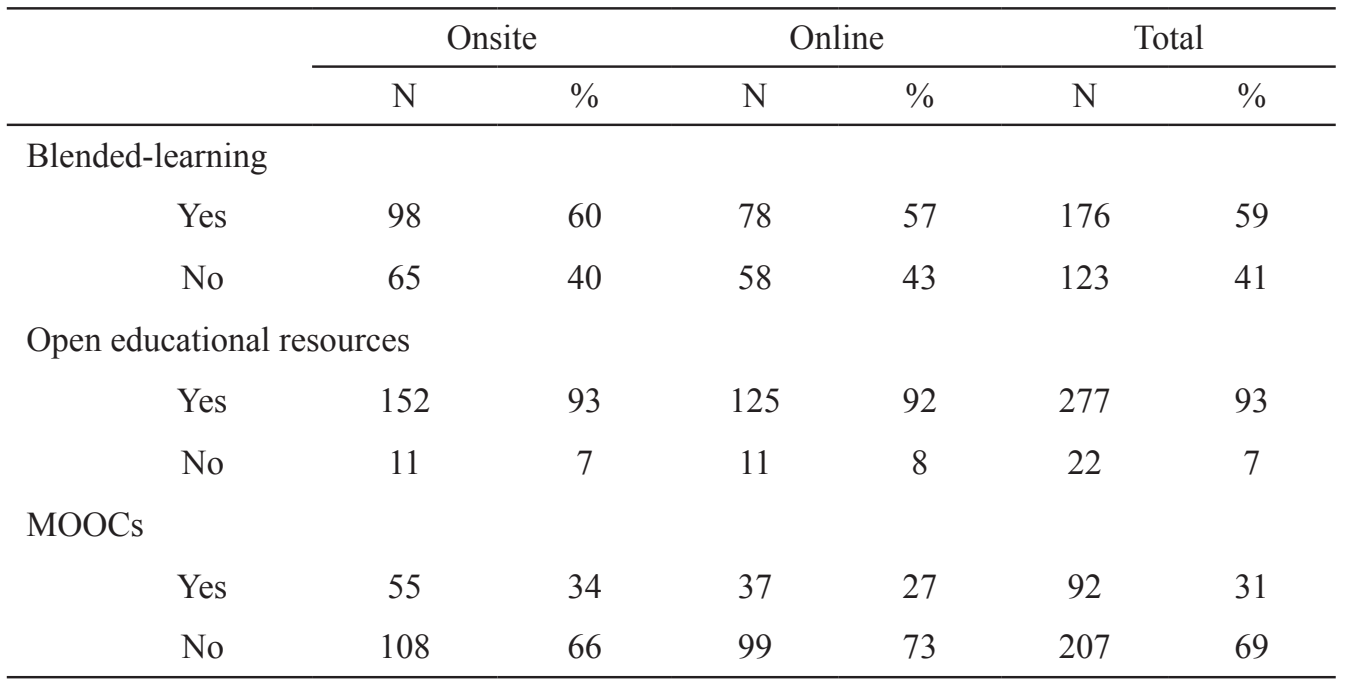

\subsubsection{Ratings of learning experiences}

Survey respondents also rated their experiences with the summer school. Onsite learners were presented with 25 Likert scale items, and the Cronbach's alpha for these items was .95. Online students responded to 28 Likert Scale items, and the Cronbach's alpha for these items was .95. Mann-Whitney $\mathrm{U}$ Tests were administered to compare their ratings.

Overall perspective. According to Table 5 , compared to their online counterparts, the onsite students rated their course experiences significantly higher on the following Likertscale items (1-5, higher score means more positive):

Table 5. Satisfactions with the course experiences.

\begin{tabular}{|c|c|c|c|c|c|c|c|c|}
\hline & Good & Easy & Satisfactory & Functional & Exciting & Flexible & $\begin{array}{l}\text { Improving } \\
\text { oneself }\end{array}$ & $\begin{array}{l}\text { Worth } \\
\text { recommendation }\end{array}$ \\
\hline \multicolumn{9}{|l|}{ Mean } \\
\hline Onsite & 3.93 & 3.61 & 3.91 & 3.88 & 3.87 & 4.09 & 4.01 & 4.29 \\
\hline Online & 3.63 & 3.32 & 3.51 & 3.47 & 3.54 & 3.76 & 3.76 & 4.07 \\
\hline $\mathrm{U}$ & 8990.50 & 8877.50 & 8531.50 & 8345.50 & 9008.50 & 8926.50 & 9362.00 & 9618.50 \\
\hline Z & -3.09 & -3.22 & -3.65 & -3.94 & -2.97 & -3.17 & -2.46 & -2.12 \\
\hline$\rho$ & 0.002 & 0.001 & 0.000 & 0.000 & 0.003 & 0.002 & 0.014 & 0.034 \\
\hline
\end{tabular}


- very good vs. very bad;

- easy vs. difficult;

- satisfactory vs. frustrating;

- sufficient vs. insufficient regarding functionality;

- exciting vs. dull;

- flexible vs. rigid;

- improving vs. not improving oneself; and

- worthy vs. unworthy of recommendation

Both groups also responded to two statements about their general learning experiences (1-5 Likert-scale: $1=$ strongly disagree; $5=$ strongly agree). Onsite $(\mathrm{M}=4.28)$ and online ( $(\mathrm{M}=4.12)$ students agreed equally to this statement: "I hope to continue learning in this way, and I will also recommend this mode of learning to others," $U=10175.50, \rho=$ .189. However, compared with distant learners $(M=3.80)$, students on campus $(M=4.13)$ agreed more strongly to the other statement: "I am satisfied with my learning achievements," $\mathrm{U}=9011.50, \rho=.003$.

Next, respondents' ratings of specific aspects of their course experiences (1-5 Likert-scale: $1=$ strongly disagree; $5=$ strongly agree) were compared (see Table 6). Below the researchers have summarized the results:

Technology quality and userfriendliness of the Web environment. No statistically significant difference in the online and onsite students' ratings was detected, and they both agreed that the CMS was easy to use and reliable:

- The course system's interface was userfriendly.
- The course system was reliable.

- It was not difficult to complete work in the system.

Quality of instructional interactions. Compared with distant participants, onsite students were more likely to agree to the statements related to instructional interactions:

- The interactions with the instructor were great during the learning process.

- The interactions with the peers were great during the learning process.

- I have received satisfactory support to help me deal with technical and other logistics issues.

- My individual learning needs have been satisfied.

Quality of instructional content. Both online and onsite students were equally satisfied with the quality of instructional content and the instructional arrangement, and they agreed that the sign-in procedure motivated them to learn better:

- The domestic and international experts brought in multiple views, which broadened my own perspective.

- The presentation materials that were uploaded in advance were helpful for my preview.

- The requirements of signing-in and signing- out encouraged me to attend the presentations on time.

Design of Learning Assessment. Both on- and off- campus students liked the design of learning assessment and agreed that the awards motivated their learning: 
- The requirement of completing quizzes by the due dates encouraged me to master the learning content.

- Through the whole group and the whole class peer evaluations, we experienced high efficiency of the course system.

- The learning awards encouraged me to put more effort into my study.

Additionally, each group was asked to indicate their opinions about the statements that were uniquely relevant to their situations. The results reflected their overall view of the blended or online learning. Onsite students agreed that blended learning was more effective than face-to-face learning only, although they thought the face-to-face component was important:

- It was very important to have face-to-face classroom learning (average rating $=4.32$ ).
- Blended instruction was superior than face-to-face instruction in the achievement of learning outcomes (4.12).

Distant participants appreciated the support that they had received from their peers and were generally in favor of online learning:

- I have gained support from my classmates for my learning (4.15).

- $\quad$ Although I was joining from a distance, I did not feel lonely (4.07).

- Online learning was economical, and I could learn without having to travel (4.24).

- Although I was participating from a distance, I was not interrupted by other issues during my learning (3.46).

- Online instruction was superior than faceto-face instruction in the achievement of learning outcomes (3.02).

Table 6. Ratings of specific aspects of course experiences.

\begin{tabular}{cllcccc}
\hline & \multicolumn{2}{c}{ Mean } & \multirow{2}{*}{$\mathrm{U}$} & $\mathrm{Z}$ & $\rho$ \\
\cline { 2 - 3 } & Onsite & Online & & & \\
\cline { 2 - 3 } User-friendliness & 3.94 & 3.75 & 9787.5 & -1.86 & 0.063 \\
System reliability & 3.46 & 3.38 & 10626.5 & -0.65 & 0.516 \\
Ease of use & 3.77 & 3.67 & 10503.5 & -0.83 & 0.404 \\
Instructor interaction & 4.00 & 3.24 & 6463.5 & -6.51 & 0.000 \\
Peer interaction & 4.13 & 3.81 & 9188.5 & -2.70 & 0.007 \\
Support & 4.02 & 3.72 & 9062.0 & -2.89 & 0.004 \\
Individual needs & 3.96 & 3.58 & 8794.5 & -3.24 & 0.001 \\
Multiple perspectives & 4.36 & 4.39 & 10841.0 & -0.36 & 0.718 \\
Preview & 4.22 & 4.19 & 10786.5 & -0.43 & 0.667 \\
Attendance & 4.10 & 4.21 & 10153.5 & -1.34 & 0.179 \\
Quiz & 4.10 & 4.08 & 11073.5 & -0.02 & 0.988 \\
Peer evaluation & 4.07 & 4.04 & 10828.0 & -0.37 & 0.714 \\
Learning awards & 3.99 & 3.98 & 10825.5 & -0.37 & 0.713 \\
\hline
\end{tabular}




\subsubsection{Qualitative feedback from learners}

Following students' rating of their experiences, survey respondents were asked: "Do you have any suggestions or comments about your online/blended learning experiences?" Altogether 299 students, including 163 onsite and 136 online learners, responded to this question. Two coders categorized their opinions. The main purpose was to identify the major issues that the students had experienced so that adjustment towards the design and management of the summer school could be made in the future. The first coder served as an expert and led an instructional session, but was not involved in the daily management of the summer school. The other coder worked as a support staff member and assisted the management of the summer school. Their different experiences with the summer school supplemented each other.

As mentioned earlier, a coding scheme was first developed following the grounded theory approach. Through continuous interaction with the text, the two researchers identified seven categories of major issues.
Additionally, although participants were asked for suggestions to enhance their learning experiences, quite a few of them provided positive comments about the summer school, appreciating this learning opportunity. Their comments were placed under "positive." There were also some comments that were very general or vague, which were placed under "other."

Some of the students mentioned more than one category in their feedback; therefore, their comments were segmented, resulting in 215 and 190 comments from the onsite and online groups, respectively. After an initial training using the first 80 comments, the coders individually coded the rest of the data. The achieved Cohen's Kappa was .92. All the differences were resolved based on a discussion. Table 7 summarizes the coding results. Researchers calculated the number of respondents from onsite group who had reported each category and the corresponding percentage within the total 163 onsite students who had responded to this survey question. The same analysis was also conducted for online students who had answered this question and for all the respondents.

Table 7. Summary of Coding Findings.

\begin{tabular}{|c|c|c|c|c|c|c|c|}
\hline & \multicolumn{2}{|c|}{ Onsite } & \multicolumn{2}{|c|}{ Online } & \multicolumn{2}{|c|}{ Sum } & \multirow{2}{*}{$\begin{array}{c}\text { Examples of student comments (Originally in } \\
\text { Chinese) }\end{array}$} \\
\hline & $\mathrm{N}$ & $\%$ & $\mathrm{~N}$ & $\%$ & $\mathrm{~N}$ & $\%$ & \\
\hline $\begin{array}{l}\text { Basic } \\
\text { Technology } \\
\text { Support }\end{array}$ & 41 & 25 & 74 & 54 & 115 & 38 & $\begin{array}{l}\text { - An online student: Sometimes the video } \\
\text { broadcasting was not smooth, and the system } \\
\text { was not stable. }\end{array}$ \\
\hline $\begin{array}{l}\text { Advanced } \\
\text { Technology } \\
\text { Improvement }\end{array}$ & 11 & 7 & 9 & 7 & 20 & 7 & $\begin{array}{l}\text { - An onsite student: A news announcement } \\
\text { column could be added to the course system to } \\
\text { provide students with reminders of the activities } \\
\text { of the days. Some students missed some of } \\
\text { the activities because they did not pay enough } \\
\text { attention to the schedule. }\end{array}$ \\
\hline Presentations & 8 & 5 & 7 & 5 & 15 & 5 & $\begin{array}{l}\text { - An onsite student: For learners whose } \\
\text { English are not so good, it might be difficult } \\
\text { to understand the presentations completed in } \\
\text { English. Could we have an interpreter? }\end{array}$ \\
\hline
\end{tabular}




\begin{tabular}{|c|c|c|c|c|c|c|c|}
\hline Interaction & 36 & 22 & 21 & 15 & 57 & 19 & $\begin{array}{l}\text { - An onsite student: I hope there will be } \\
\text { more group activities in the future. }\end{array}$ \\
\hline $\begin{array}{l}\text { Online } \\
\text { Learning } \\
\text { support }\end{array}$ & 9 & 6 & 19 & 14 & 28 & 9 & $\begin{array}{l}\text { - An online student: It was hard to concentrate } \\
\text { for a long time when I was learning online. }\end{array}$ \\
\hline $\begin{array}{l}\text { Scheduling } \\
\text { and } \\
\text { management }\end{array}$ & 33 & 20 & 15 & 11 & 48 & 16 & $\begin{array}{l}\text { - An onsite student: Suggestion: Providing } \\
\text { access to external Internet. }\end{array}$ \\
\hline Assessment & 17 & 10 & 7 & 5 & 24 & 8 & $\begin{array}{l}\text { - An onsite student: Students might be biased } \\
\text { during conducting team evaluation and were not } \\
\text { objective. }\end{array}$ \\
\hline Positive & 49 & 30 & 28 & 21 & 77 & 26 & $\begin{array}{l}\text { - An onsite student: We appreciate such a } \\
\text { learning opportunity provided by Peking } \\
\text { University. We were able to experience the } \\
\text { important role that new technologies played } \\
\text { in our learning. Hopefully we will be able to } \\
\text { participate in similar activities again in the } \\
\text { future. }\end{array}$ \\
\hline Other & 11 & 7 & 10 & 7 & 21 & 7 & - An onsite student: None. \\
\hline
\end{tabular}

Basic technology support. One quarter of onsite and over one half of online students reported having encountered technological challenges while attempting to access the instructional content. Among them, 30 onsite and 35 online learners complained about the stability of the system. Sometimes the system crashed when an overwhelming number of learners tried to access it synchronously. Two onsite and 42 online students mentioned issues relating to watching live-broadcasted instructional sessions. The video streaming was not smooth enough, and sometimes it was hard for them to see the images or hear the audio clearly. The latter was due to a combination of issues relating to synchronous access, angles of video shooting, and video formats.

Advanced technology improvement. In total, $7 \%$ of the learners suggested improving the user-friendliness and aesthetic appearance of the system interface and introducing new features. For instance, four distant learners recommended adopting the "three-part-separated screen mode" for video broadcasting, "making it possible for the students to choose between watching instructor video and associated PowerPoint at the same time and watching one of them only." Other suggestions included adding the capacity to quickly locate their team members from the class list and strengthening the notification feature, which updated them regarding instructional activities.

Presentations. Altogether 5\% of the students offered their ideas to improve experts' presentations such as inviting more experts to discuss more academic areas or exploring some of the topics further. Two onsite and five online learners also expressed difficulties with understanding the presentations completely in 
English.

Interactions. Nearly one fifth of the learners suggested improving interactions. Twenty-one onsite and three online students commented on their group collaboration. They suggested adding more collaborative learning opportunities and initial ice-breaking activities and taking into consideration levels of expertise and research interests during group assignments. Moreover, four onsite students mentioned the inconvenience of communicating with online team members. Four onsite and one online students also proposed organizing collective activities for them to know more classmates. Additionally, seven onsite and eleven online participants asked for "more opportunities to interact with the instructors."

Online learning support. Both onsite and online participants had engaged in online learning, although to different extents. Overall, $6 \%$ of onsite and $14 \%$ of online students demanded increased support for their online learning. Among them, eight distant learners encountered challenges trying to adapt to online learning, including remaining focused while watching live-broadcasted presentations, staying motivated, and self-management of learning. Similarly, two onsite students also asked for closer monitoring of their online learning. Additionally, four onsite and five online learners complained about the lack of replies to the questions that they had posted online. Four online students also suggested the organizers to upload the recording at the end of each instructional session, instead of at the end of the summer school, to facilitate their learning.

Scheduling and management. Altogether $20 \%$ of onsite and $11 \%$ of online learners proposed improving overall scheduling and management of the summer school and suggested increasing staff support. Five onsite and three online students found it challenging to keep up with the deadlines or to probe further on their own those topics presented by the experts. One onsite and four online students preferred receiving more frequent, timely, and consistent notifications from the organizers. With regard to student assignment and admission, three online learners asked for more opportunities to attend the summer school onsite; two students recommended the organizers to screen applicants because they found some of their peers' final papers of inferior quality. Students on campus also complained about the inconvenience of traveling from off-campus, having to bring computers to complete the sign-in procedure, and the lack of external Internet access in the classroom.

Assessment. In total, $10 \%$ of onsite and $5 \%$ of online students provided their opinions to enhance the learning assessment. Seven onsite and four online participants suggested improving the quiz design such as adding essay questions and improving the quiz questions to inspire them to think deeper. Respondents also felt it difficult to finish a high quality paper in two weeks, preferred to attempt a quiz more than once, and found peer feedback not always helpful.

\section{Discussion}

Running this summer school as a MOOC allowed the organizer to enroll 1.5 times more students than the previous year. However, distant learners in this study had lower completion rates than their peers on campus. Nevertheless, their completion rate (41\%) was much higher than the average reported by Western researchers $(15 \%)$. It was also noted that online learners who managed to complete all the course work were able to achieve satisfactory learning performance. There was no statistically significant difference 
between the onsite and online learners' average assignment scores, and both groups were equally likely to win two of the learning awards. Thus, making every effort possible to retain online learners and to support them towards the completion of the course work is important. Learners' comments obtained from this study about their learning experiences could help guide this effort.

Experimenting Flipped Classroom Model. During this summer school, technologies have become one of the major issues, especially when students tried to use the same feature synchronously. Additionally, learners longed for more opportunities to discuss and collaborate together. Other MOOC practitioners have shared related observations: MOOC participants' discussions were short-lived and did not lead to the building of meaningful relationships (Gillani, \& Eynon, 2014; Guthrie, 2012), while social interaction played a significant role in MOOC participants' successful completion of the course (Yang et al., 2013). A possible solution is to integrate the flipped classroom model. Currently, some of the Chinese universities such as Shanghai Jiao Tong University and Fudan University have started exploring this instructional model (Gong, 2013b, 2014). Similarly, Bruff, Fisher, McEwen, and Smith (2013) introduced a MOOC from Stanford to their students at Vanderbilt University. Students watched the online MOOC videos on their own, and used their face-to-face meeting time to engage in group activities and class discussions.

Flipped classroom model integrates online direct instruction and face-to-face constructive learning activities, leading to increased instructional interactions and more personalized learning experiences (Bergmann, Overmyer, \& Wilie, 2013). It might be helpful to first experiment with this format in the sessions led by overseas experts. Instructors could record their presentations beforehand, ask students to watch the videos on their own prior to their sessions, and use the synchronous meeting times to engage students in active learning activities. Adopting this strategy could also decrease the technical challenge to the CMS.

Enhancing support for students' learning. Both online and onsite participants experienced challenges with self-directed online learning. Similarly, Graham and Fredenberg (2015) noticed in their study some participants struggled with open learning. They recommended making this a prerequisite for learners to have prior exposure to traditional asynchronous learning. In this study, over $40 \%$ of students did not have experience with blended learning (see Table 4), which might have contributed to the difficulties that they had encountered. It would be helpful to arrange an orientation activity at the beginning, providing an overview of the schedule and introducing the expectations and possible challenges of self-directed learning. Practical advice from previous studies (e.g. Hill, 2002) could also be shared to help students develop an individual agenda for their learning.

Checkpoints could also be added in order to support students to better manage their time. It was noted that some learners procrastinated and spent most of the last days working on their final papers. The issue of time management seemed more challenging for online learners whose average final paper score was lower than that of their onsite students. Therefore, it would be helpful to ask all the students to submit a brief proposal for their final paper at the end of the first week. Quite a few learners also suggested enhancing the course notification feature of the CMS. In addition to adding new technical abilities, increasing staff support and providing students with reminders and updates of instructional 
activities in a consistent and timely manner is necessary. Additionally, due to the lack of support staff, it was impossible to provide timely responses to the questions that students posted online. One possible solution would be to encourage students to respond to peers' questions. Learners could submit their evidence of having provided their peers with support at the end of the summer school to receive extra credit. As another approach to resolve this issue, Coursera recently piloted a peer-mentoring program (http://www.coursera. community/\#mentor) and recruited students who had completed a course with a high score to serve as mentors when the same course was offered again. It is meaningful to continue exploring strategies in order to provide MOOC learners timely assistance, which could greatly enhance the possibility of their learning success (Hew \& Cheung, 2014).

Unique challenges to Chinese learners. During the summer school, some students found it challenging to understand the presentations in English, an issue already addressed in literature review. Recruiting students with advanced language skills to volunteer and help with subtitling or assist their peers could help.

Students also suggested arranging more collective activities, either online or face-toface, with the main purpose of socializing and getting acquainted with more peers. Although learners generally have a desire to know one another, their requests to spend time together in a large group seemed to be influenced by Chinese culture. In Chinese universities, students who have been admitted into the same program usually stay together until they graduate. Throughout the years, whole class activities such as field trips and parties are organized. Organizing these types of activities for this current MOOC is difficult, due to the lack of staff and financial resources, short duration of time, a big enrollment number, and admission of both online and onsite students. However, a field trip was successfully arranged for onsite students, and they really appreciated that effort. Additional icebreaking activities (Bonk \& Khoo, 2014) could also be introduced to engage both the onsite and online participants synchronously.

\section{Conclusion}

In this first empirical research about a Chinese MOOC, the on- and off-campus students' learning performances and experiences were compared. Lessons learned from the actual implementation and ideas to improve the summer school were shared. Findings from the study enrich the current limited educational research of MOOCs and can be useful for practitioners engaging in MOOC practices, especially those interested in introducing MOOCs into China. Due to limited resources available, only a medium size MOOC was experimented. Future research would be conducted to explore MOOCs enrolling more Chinese students.

\section{Acknowledgements}

We appreciate the Graduate School of Peking University for sponsoring the summer school of "New Media and Learning" within the framework of "Innovative Education for Graduate Students," the Computer and Network Center of Peking University for their technology support, and the contributions to this summer school project from these colleagues: Ms. Jingmin Miao, Professor Xiaomeng Wu, Professor Aihua Wang, and Mr. Baijie Yang. 


\section{References}

Akkoyunlu, B., \&Yilmaz-Soylu, M. (2008). Development of a scale on Learners' Views on blended learning and its implementation process. Internet and Higher Education, 11(1), 26-32.

Bergmann, J., Overmyer, J.,\&Wilie, B. (2013) The Flipped class: Myths vs. Reality. Retrieved from http://www. thedailyriff.com/articles/the-flipped-classconversation-689.php

Bernard, R. M., Abrami, P. C., Lou, Y., Borokhovski, E., Wade, A., Wozney, L., ... Huang, B. (2004). How does distance education compare with classroom instruction? A Meta-Analysis of the empirical literature.Review of Educational Research, 74(3), 379-439.

Bonk, C. J., \& Khoo, E. (2014). Adding some TEC-VARIETY: 100+ activities for motivating and retaining learners online. Amazon CreateSpace.

Bruff, D. O., Fisher, D. H., McEwen, K. E., \& Smith, B. E. (2013). Wrapping a MOOC: Student perceptions of an experiment in blended learning. MERLOT Journal of Online Learning and Teaching, 9(2), 187199.

Butcher, N. (A. Kanwar\& S. Uvalic'-Trumbic' Eds.) (2011).A basic guide to Open Educational Resources (OER). Commonwealth of Learning \& UNESCO. Retrieved from http://www.col.org/ PublicationDocuments/Basic-Guide-ToOER.pdf

Clark, R. E. (1994). Media will never influence learning. Educational Technology Research and Development, 42(2), 21-29.

Daniel, J. (2012). Making sense of MOOCs: Musings in a maze of myth, paradox and possibility. Journal of Interactive Media in Education. Retrieved from http://wwwjime.open.ac.uk/jime/article/view/201218
Gasevic, D., Kovanovic, V., Joksimovic, S., \& Siemens, G. (2014). Where is research on massive open online courses headed? A data analysis of the MOOC Research Initiative. The International Review of Research in Open and Distributed Learning, 15(5), 134-176.

Gillani, N., \&Eynon, R. (2014). Communication patterns in massively open online courses. The Internet and Higher Education, 23, 18-26.

Gong, Y. (2013a). Interviews with three major US platforms, Coursera, Udacity, and edX: Taking local situations into consideration during the introduction of MOOCs (in Chinese). Distance Education in China, (14), 22-23

Gong, Y. (2013b).Fudan University: MOOC is challenging traditional instruction (in Chinese). Distance Education in China, (14), 20-21

Gong, Y. (2014). Shanghai Jiao Tong University: Construction of MOOC and promotion of blended instruction (in Chinese). Distance Education in China, (2), 2-4

Graham, L., \&Fredenberg, V. (2015). Impact of an open online course on the connectivistbehaviours of Alaska teachers. Australasian Journal of Educational Technology, 31(2), 140-149.

Grimmelmann, J. (2013). The Merchants of MOOCs. University of Maryland Legal Studies Research Paper No. 2014-6. Retrieved from http://papers.ssrn.com/ sol3/papers.cfm?abstract_id=2358253

Guthrie, D. (2012). Jump off the Coursera bandwagon. The Chronicle of Higher Education. Retrieved from http:// chronicle.com/article/Jump-Off-theCoursera/136307/

Hew, K. F., \& Cheung, W. S. (2014). Students' and instructors' use of massive open online courses (MOOCs): Motivations and challenges. Educational Research Review, 
$12,45-58$.

Hill, J. (2002). Overcoming obstacles and creating connections: Community building in Web-based learning environments. Journal of Computing in Higher Education, 14(1), 67-86.

Jaggars, S. S., \&Xu, D. (2010). Online learning in the Virginia community college system.New York: Columbia University, Teachers College, Community College Research Center. Retrieved from http://ccrc.tc.columbia.edu/media/k2/ attachments/online-learning-virginia.pdf

Jordan, K. (2014). Initial trends in enrolment and completion of massive open online courses. The International Review of Research in Open and Distributed Learning, 15(1), 133-160.

Jordan, K. (2015). MOOC completion rates: The data. Retrieved from http://www. katyjordan.com/MOOCproject.html

Li, F., Zhou, M., \& Fan, B. (2014). Can distance education increase educational equality? Evidence from the expansion of Chinese higher education.Studies in Higher Education, 39(10), 1811-1822.

Liu, Z. (2013a). It is necessary to overcome language challenges to study MOOC courses from abroad (in Chinese). Distance Education in China, (14), 25

Liu, Z. (2013b). Chinese MOOC: Being active instead of being passive during the transformation. An interview with Jianli Jiao, the Deputy Dean of School of Information Technology in Education and Deputy Director of Future Education Research Center at South China Normal University (in Chinese). Distance Education in China, (14), 16-19

Liu, Z. (2013c). The belated Chinese MOOC: When the storm of MOOCs arrives (in Chinese). Distance Education in China, (14), 12-15

Liyanagunawardena, T. R., Adams, A. A., \& Williams, S. A. (2013). MOOCs: A systematic study of the published literature
2008-2012. The International Review of Research in Open and Distributed Learning, 14(3), 202-227.

López-Pérez, M. V., Pérez-López, M. C., \& Rodríguez-Ariza, L. (2011). Blended learning in higher education: Students' perceptions and their relation to outcomes. Computers \& Education, 56(3), 818-826.

McAuley, A., Stewart, B., Siemens, G., \& Cormier, D. (2010). The MOOC model for digital practice. SSHRC Knowledge Synthesis Grant on the Digital Economy. Retrieved from http://www.elearnspace. org/Articles/MOOC_Final.pdf

Moore, M. (1989). Editorial: Three types of interaction. American Journal of Distance Education, 3(2), 1-7.

Paechter, M., Maier, B., \& Macher, D. (2010). Students' expectations of, and experiences in e-learning: Their relation to learning achievements and course satisfaction. Computers \& Education, 54(1), 222-229.

Rodriguez, C. O. (2012). MOOCs and the AIStanford like courses: Two successful and distinct course formats for massive open online courses. European Journal of Open, Distance and ELearning. Retrieved from http://www.eurodl.org/?p=Special\&sp=ini t $2 \&$ article $=516$

Sandeen, C. (2013). Assessment's place in the new MOOC world.Research \& Practice in Assessment, 8, 5-12

Shee, D. Y., \& Wang, Y.-S. (2008). Multicriteria evaluation of the web-based e-learning system: A methodology based on learner satisfaction and its applications. Computers \& Education, 50(3), 894-905.

Siemens, G. (2012) MOOCs are really a platform. eLearnspace. Retrieved from http://www.elearnspace.org/ blog/2012/07/25/moocs-are-really-aplatform/

Siemens, G., Irvine, V. \& Code, J. (2013). Guest Editors' Preface to the Special Issue on MOOCs: An academic perspective 
on an Emerging technological and social trend. MERLOT Journal of Online Learning and Teaching, 9(2), iii-vi. Retrieved from http://jolt.merlot.org/ vo19no2/siemens_editorial_0613.htm

Simpson, O. (2013). Student retention in distance education: are we failing our students? Open Learning: The Journal of Open, Distance and E-Learning, 28(2), 105-119.

Strauss, A. L., \& Corbin, J. (1990). Basics of qualitative research: Grounded theory procedures and techniques. Newbury Park, CA: Sage.

Sun, P.-C., Tsai, R. J., Finger, G., Chen, Y.-Y., \&Yeh, D. (2008). What drives a successful e-Learning? An empirical investigation of the critical factors influencing learner satisfaction.Computers \& Education, 50(4), 1183-1202.

Yang, D., Sinha, T., Adamson, D., \& Rose, C. P. (2013). Turn on, tune in, drop out: Anticipating student dropouts in massive open online courses. In Proceedings of the 2013 NIPS Data-Driven Education Workshop (Vol. 11, p. 14).

Zhu, Z., Bi, L., Qi, X., Li, Y., Chen, Y., \& Song, Y. (2011). The mining analysis on the dropout rate of modern distance education: Based on the data collected from 1999 to 2009 in Anhui province of China (in Chinese). Journal of Distance Education, (4), 18-25.

\section{Contact the Author}

\section{Weichao Chen}

School of Medicine, University of Virginia, USA

Email: Weichao.Chen@virginia.edu

\section{Jiyou Jia}

Department of Educational Technology, Graduate School of Education, Peking University, China

Email: jjy@pku.edu.cn 